\title{
EL MUNDO FILOSÓFICO DE MIGUEL ÁNGEL
}

Pico de la Mirándola, siguiendo a Platón en la forma de expresar la filosofía a través del mito, ha expuesto uno de los más hermosos, en el que se hace patente el sentido de la filosofía que movería el mundo en que surge la obra de Miguel Angel. En el Discurso sobre la dignidad del hombre, relata Pico cómo el creador, el demiurgo, al terminar la creación del universo se sintió movido a crear un ser que diese sentido a esa creación, que fuese el parlante testigo de ella; un ser capaz de conocer el fondo último de esa obra y de amarla por su belleza. Pero, ¿qué sucedía? La creación había sido total, el demiurgo había hecho de su obra una obra tan plena y extraordinaria que no podía ya ser mejorada; no podía ser, inclusive, recreada. "Pero entre los eternos arquetipos de las cosas no había ya ningún modelo para un nuevo brote -dice Pico-, ni el creador poseía entre sus tesoros don alguno que pudiera otorgar como dote a su nuevo hijo, ni encontraba tampoco en todo el orbe terrestre un lugar en que el que había de ser contemplador de todas las cosas pudiera ocupar su puesto de observación." I Esto es, la creación, a fuerza de ser tan perfecta, tenía cerradas todas las posibilidades para una nueva creación. El creador se limita a sí mismo en su extraordinaria perfección; mejorarla hubiera significado imperfección. "En efecto - sigue diciendo Pico de la Mirándola-, el todo estaba ya colmado y a cada ćrculo - tanto el más elevado, como el más bajo, como el del centro- tenía ya asignados los distintos seres de acuerdo con el orden correspondiente. Asi pues, determinó el Supremo Hacedor, ya que no podía dotar a la nueva criatura de un bien propio y particular, que poseyera en común con los otros seres los dones que a ellos había conferido."2 Esto es, el hombre, la última criatura, sin ser dueño de ningún don, los tendria todos en común con el resto de la creación. Seria al mismo tiempo la criatura más rica y la más menesterosa, dueño de posibilidades universales dentro de la carencia absoluta de ellas. "Formó pues al hombre -agrega Pico-, según una imagen común que no presentaba distinciones, y le dijo mientras lo colocaba en el centro del mundo: 'Adán, no te he señalado ningún puesto preciso, no te he dado una figura propia, ni te he conferido un patrimonio exclusivo, para que tú mismo, escogiendo de acuerdo con tu propio deseo y determinación cualquier puesto, cualquier figura y cualquier don, puedas hacerlos tuyos.' " 3 Esto

1 Ernest Cassirer, Individuo y cosmos en la filosofia del Renacimiento, Emecé Editores, Buenos Aires, 1951, pág. 114.

2 Cassirer, op. cit., págs. 114-5.

3 Cassirer, op. cit., pág. 115 . 
es, el creador, no pudiendo ya recrearse, hacia del Hombre el creador de esa creación. Un recreador que sólo podría ser tal si actuaba, como su creador, libre y espontáneamente. La creación, el todo, quedaba sometido a la nueva criatura, que tomaría de ella los elementos para nuevas creaciones. Era de esta forma como el demiurgo trascendía su perfección dando el don de la creación, esto es, el de la libertad que elige del todo para nuevas creaciones, al ente que había surgido huérfano de los dones específicos del resto de las criaturas. "Todos los demás seres - agrega el creador del mito de Pico- han recibido de mi mano una naturaleza precisamente determinada que conservan, puesto que está sometida a leyes rigurosas, que de antemano he establecido. Tú, en cambio, eres el único a quien no atan trabas; sé, pues, tú mismo el que te las impongas por la voluntad que te concedo. Te he colocado en el centro del mundo para que desde aquí puedas contemplar y ver mejor todo cuanto está a tu alrededor. Te he creado como criatura que no es exclusivamente ni celeste ni terrestre, ni mortal ni inmortal, a fin de que tú mismo te puedas forjar y superar libremente y puedas asumir cualquiera de las formas que elijas. Puedes degenerar hasta convertirte en animal, como puedes regenerarte hasta llegar a lo divino." "Los animales nacen trayendo del cuerpo de la madre todo cuanto deben tener; los espíritus superiores desde el principio o desde muy poco tiempo después son lo que serán por toda la eternidad. En cambio, al hombre, en el momento de crearlo, le ha conferido su padre la semilla y el germen de toda vida. Cualquiera de las semillas que el hombre cultiva germinará y producirá fruto. Si se trata de un brote vegetal, se convertirá en planta; si sigue la sensualidad, será una bestia; si cultiva en sí mismo el poder de la razón, se convertirá en un ser celestial; si sigue a la inteligencia, será hijo de Dios y ángel." 4 Todos los seres están hechos; sólo el hombre ha de hacerse y, al hacerse, rehará, igualmente, a la creación. El valor, el sentido de sí mismo y del mundo del que es parte, dependerán del hombre. Dios mismo, como dirán más tarde los románticos, dependerá de esta criatura al mismo tiempo fuerte y débil. Por eso tenía sentido la Biblia al decir que el hombre había sido creado a imagen y semejanza de su creador. Imagen de Dios, creador como él, pero, al mismo tiempo, criatura. En la Capilla Sixtina se puede ver a este primer hombre, Adán, en la forma como lo concebía la filosofía de Pico de la Mirándola en su mito. Allí está el hombre, pintado por Miguel Angel, con esa pujanza que le caracterizará. El hombre lleno de posibilidades, fuerte, poderoso; pero, al mismo tiempo, abandonado en sus movimientos, apenas con la fuerza suficiente para extender su mano hacia el creador, cuyo dedo, sin llegar a tocarlo, le señala el destino del que ha de ser el único responsable. Adán, el hombre, respondiendo de toda la creación.

Miguel Ángel ha formado su espíritu dentro de una filosofía que busca

4 Cassirer, op. cit., pág. 115. 
conciliar dos mundos que parecen opuestos, el del hombre y el de Dios, el humanismo y la teología. Es en Florencia, precisamente, en donde bajo los auspicios de su gran protector, Lorenzo de Médicis, el Magnífico, la Academia discutía la forma de hacer compatibles ambos mundos, los mundos que ya Platón describía separados, pero que se unían en ese ente llamado hombre. El joven escultor se ha encontrado, y sentado a la misma mesa del palacio de los Médicis, con Marcilio Ficino, intérprete de Platón, con Pico de la Mirándola, cuyo discurso hemos citado, con el humanista Angelo Poliziano, con Luigi Pulci, creador de romances burlescos y con otros muchos artistas y filósofos, empeñados todos ellos en hacer del hombre el centro del maravilloso mundo que surgía ante sus ojos. El mundo y la carne, la carne que hace del hombre un hombre, van dejando de ser lo accidental, lo pecaminoso, lo que debe ser rechazado. Es en el siglo xirr cuando otro italiano se anticipa a esta nueva actitud cantando su amor al mundo, a las criaturas que lo forman y a la carne, que si bien limita al hombre, lo define como tal y lo hace instrumento de su propia recreación; este hombre fue Francisco de Asís.

El mundo y la carne van dejando de ser castigo y prisión. El mundo no es ya un lugar de destierro ni la carne la prisión del alma; ambos son el material y el instrumento de la recreación que se ha encomendado al hombre. El mundo es bello, como bello es el cuerpo humano; y lo son por el solo hecho de haber sido creaciones divinas. Pero es al hombre a quien toca descubrir y expresar esa belleza; del único don especial que posee, la libertad de elección, depende el que ese mundo y él mismo sigan siendo bellos, buenos y dotados de los más altos valores. El hombre ha sido cargado con la más grande y más extraordinaria de las responsabilidades: mantener la belleza y la bondad de la creación divina. ¿Podrá con tan grande carga?

Éste será uno de los grandes temas de la filosofía renacentista. ¿Puede el hombre captar y hacerse responsable de la creación, de una creación infinita? En términos filosóficos, ¿puede conocer lo infinito y absoluto, puede conocer a Dios? Podrá, desde luego, por gracia, como un don especial de creador; pero no es esto lo que importa. Lo que importa es cómo yo, hombre, puedo, dentro de mis limitaciones, alcanzar este conocimiento. No por gracia, sino por mí mismo, dentro de mi limitada naturaleza. Aún resuenan los ecos de la filosofía de dos franciscanos, ingleses ambos, Duns Escoto y Guillermo de Occam, que ha destruido todo el armazón filosófico en que sc apoyaba la Edad Media: la racionalidad de Dios, del mundo y sus criaturas, entre ellas el hombre. Gracias a esta racionalidad, el hombre, ente racional, podía conocer a Dios y a la creación. Pero no hay tal: ni Dios es racional ni la naturaleza, creada por él, lo es. El único ente racional es el hombre. El mundo, y esto lo va a demostrar el empirismo, que tiene su fuente en esa filosofía, puede coincidir con la razón, enmarcarse dentro de su conocimien- 
to, no porque sea racional, sino porque el hombre tiene capacidad para racionalizar el mundo. ¿Cómo lo racionaliza? Por la experiencia, parte por parte, experimentándola, deduciendo leyes que serán válidas hasta que la misma experiencia no demuestre lo contrario. En igual forma se podrá captar, conocer, llegar a lo absoluto: parte por parte, trozo por trozo.

El conocimiento - nos dirá Nicolás de Cusa, cuya doctrina orientará el pensamiento filosófico del mundo de Miguel Angel- se encuentra limitado frente a lo infinito y absoluto; pero dentro de esta limitación puede, sin embargo, captar en lo finito y limitado trozos de lo infinito e ilimitado. Esto es, el conocimiento humano puede someter, limitar, paso a paso, lo absoluto. También el Cusano se encuentra preocupado, no tanto por el conocimiento de Dios y de lo absoluto, como por la posibilidad humana de este conocimiento. No se quiere saber de la capacidad de Dios para hacerse conocer, ya que él todo lo puede; sino de la capacidad del hombre para este conocimiento. La capacidad del hombre, insisto, fuera de la fe y de la gracia; la capacidad del hombre para poner lo absoluto al alcance de sí mismo. Se trata de ver la unidad, el lazo de unión, de dos mundos que parecen tan opuestos. Ya Platón se había planteado este problema y por ello su filosofía causará un gran impacto en los filósofos del Renacimiento, y es a partir del platonismo cuando la filosofía renacentista planteará el problema del humanismo. Es en el hombre donde se dan los atributos de lo limitado y finito; pero, a la vez la aspiración que mueve hacia lo ilimitado y absoluto. El hombre, preso en la caverna de que hablaba Platón en su mito, reconoce en las sombras de lo limitado el cuerpo real de lo absoluto que las proyecta. Nunca podrá el hombre abarcar con su conocimiento lo ilimitado, pues dejaría de serlo; pero siempre podrá devorar, asimilar partes cada vez más amplias de ese infinito. Fausto, el hombre fáustico, está ya presente en esta filosofía del hombre que en su finitud puede devorar, sin descanso, lo infinito. Nicolás de Cusa se sirve de una metáfora para explicar la posibilidad de este conocimiento, cuando dice: "De modo que el intelecto se comporta con respecto a la verdad como el polígono con respecto a la circunferencia; en efecto, cuanto mayor sea el número de ángulos y de lados que el polígono presente, tanto más cerca de la circunferencia estará, sin que por ello, y aunque se multipliquen los lados y los ángulos infinitamente, pueda llegar alguna vez a ser la circunferencia misma; análogamente ocurre con nosotros, que sólo sabemos de la verdad tal como es, que no podemos aprehenderla con verdadera exactitud. Pues la verdad es la necesidad absoluta, que no puede ser ni más ni menos que como es; nuestro intelecto, en cambio, es mera posibilidad." $5 \mathrm{El}$ hombre, ese hombre de que nos hablaba Pico de la Mirándola, es eso, "mera posibilidad", y puede ser todo sin ser prácticamente nada en concreto. Es, precisamente, lo indefinido y por ello apto para cap-

5 Cassirer, op. cit., pág. 39. 
tar, aunque sea dentro de sus limitaciones, lo ilimitado, lo absoluto. Es el hombre, condicionado y finito, el que apunta siempre a lo infinito, sin lograr, empero, alcanzarlo nunca. Éste es el principio de la Docta Ignorancia del Cusano; el saber de las propias limitaciones, por lo cual se sabe que se ignora; saberse finito por la conciencia que se tiene de lo infinito. La verdad es inalcanzable en su ser absoluto; es lo otro, distinto de nosotros; pero no tan distinto que no seamos parte de él. Por ello el conocimiento humano, aunque limitado, es incapaz de franquear los límites de sus posibilidades, mas no por ello reconoce la menor limitación a su afán de conocer lo otro, y, sin impedimentos, se lanza a conocer lo que está más allá de sí mismo.

¿Qué sucede con este tipo de conocimiento? El hombre pone su marca en el Universo, en lo absoluto, en lo infinito. El todo es recortado por el hombre que lo pone a su alcance. La creación, como quería Pico, es recreada. El hombre esculpe en el infinito la concepción que se ha hecho de él. Dice de él que es capaz de captar lo que es capaz de ver, lo que está al alcance de su finitud ansiosa de infinitud. Por ello, escribe Nicolás de Cusa, no podemos tener una intuición de Dios que no esté determinada por la forma de su contemplación, por la forma como el hombre lo ve y lo alcanza. "Tu rostro verdadero -dice dirigiéndose a Dios- está exento de toda limitación; no es de este tamaño ni de esta calidad, no es ni espacial ni temporal, puesto que es la forma absoluta en sí, el rostro de todos los rostros." 6 El hombre, todo hombre, cada uno de los hombres, puede contemplarse en Dios y encontrar su verdad, la verdad concreta de su rostro; pero Dios es, precisamente, todos los rostros, sin ser en concreto ninguno de ellos. "Cada rostro que mira al tuyo - sigue diciendo el Cusano- al mirarlo no ve sino el suyo mismo, porque ve su propia verdad." "Asi, quien te mire con cariñosa mirada, percibirá también tu mirada cariñosa dirigida hacia él, y cuanto mayor sea el amor con que aspira a contemplarte, tanto más cariñosamente lo iluminará su mirada. Quien te sirve con enojo, encontrará también tu rostro Ileno de cólera; quien te contemple con regocijo, lo encontrará regocijado. Pues del mismo modo que a los ojos del cuerpo les parece todo rojo cuando miran a través de un cristal de ese color, así también ocurre con los ojos del espíritu, que en su limitación te miran a tí, que eres blanco y objeto de su contemplación, conforme a esa naturaleza limitada. Pues el hombre sólo puede juzgar como ser humano." ? Lo mismo sucederia si los leones, águilas o becerros contemplaran y conocieran a Dios: lo verian como tal. "¿Oh, Señor —dice Nicolás de Cusa - de qué naturaleza maravillosa es tu rostro qué el joven, si quiere concebirlo, debe representárselo juvenil; el hombre viril, viril; el anciano, senil?" 8 En Dios están todos los rostros de los hombres, Ė

6 Cassirer, op. cit., pág. 51.

7 Cassirer, op. cit., pág. 51.

8 Cassirer, op. cit., pág. $5^{2}$. 
es cada uno de los hombres, cada uno de ellos lo imagina o lo hace a su imagen y semejanza. Se ha realizado, como se ve, una extraordinaria inversión. El hombre creado, de acuerdo con la Biblia, a imagen y semejanza de su creador, se ha transformado en creador, al proyectar en Dios su propia imagen, al hacer de éste su imagen. La criatura se transforma en creadora y el creador en criatura de su criatura.

¿Cómo, pues, conocer a Dios en toda su plenitud, en todo lo que es? Buscándolo en todas sus criaturas, en todo el mundo, en todos los hombres. Pues a través de sus "creaciones" es como se ha desplazado y hecho patente. Amar el mundo, amar lo humano, amar lo particular y limitado, al igual que conocerlo, es amar y conocer la totalidad. De modo que el ideal hacia el que debe tender nuestro conocimiento no consiste en desconocer ni en desechar lo particular, sino más bien en comprender el pleno despliegue de toda su riqueza, pues sólo la totalidad del rostro nos proporciona la visión una de lo divino. Dios está, para las limitaciones del hombre, como prisionero en la realidad asequible a éste, el cual, para conocerlo y liberarlo, deberá romper, parte por parte, la prisión limitadora. Dios, la Verdad, lo absoluto, está inmerso, velado, oculto, y es el hombre con sus ojos y poder, quien debe sacarlo a flote, desvelarlo, hacerlo patente, como el escultor que con el cincel va recortando, arrancando la materia que oculta las formas que sus ojos han sabido ver dentro de la materia. Los ojos del hombre saben reconocer en las sombras que se proyectan en la Caverna, las formas ocultas de la Verdad y, reconociéndolas, se dispone a iluminarlas.

No de otra manera concibe Miguel Angel su arte. Él es, ante todo, ese recreador del mito de Pico de la Mirándola. La belleza innata, propia de la creación, es recreada, embellecida por el cincel y el pincel del gran artista, cuyos ojos descubren, dentro de la tosca piedra y el frío muro, las ocultas formas de una belleza más honda, de una belleza que estando allí no había sido vista. Pero que una vez vista es menester hacer salir a luz, dar a luz, recrear. Por ello el propio Miguel Ángel llamó a la escultura el arte que "opera a fuerza de quitar". Arrancar, quitar la materia que oculta las formas que el artista ha visto dentro de ella. "Señora -escribe el artista florentino-, en la dura y áspera piedra, el mero quitar la superficie da vida a una figura, que va creciendo mientras la piedra salta." 9 Dar vida, crear, recrear, es lo que el artista siente al golpear con el cincel la dura piedra. Detrás de la piedra se oculta el David, el Moisés, la Piedad, los esclavos y tantas y tantas extraordinarias figuras sacadas a golpes de la materia. Allí estaban dentro, esperando ser sacadas. Dentro del mármol, bella criatura de Dios, se hallaban ocultas como criaturas que lo serán del artista,

9 John Addington Symonds, Vida de Miguel Angel. Editorial Sudamericana, Buenos Aires, 1943, págs. 80-1. 
En el más grande artista no hay idea que la piedra no incluya en su aspereza. Romper del mármol el hechizo es todo lo que la mano, de obediente modo, podrá obrar por la mente en su destreza.10

dice el artista al expresar lo que podría ser el secreto de su arte. En la creación el artista ha sabido encontrar nuevas formas de creación. La belleza absoluta de la creación, al ser enfocada por los limitados ojos del hombre, toma múltiples formas de belleza que de otra manera habrian quedado ocultas. ¿Qué otra cosa sino un artista es el ideal de hombre imaginado por la filosofía del Renacimiento? Es el hombre, armado de su libertad, el que se forja a sí mismo y forja al mundo, y lo forja y se forja de acuerdo con la forma oculta que descubre en el mundo ya creado y hecho, en la creación. El hombre ya no es simple parte del todo, no es simple parte de la creación, es, además, ojo y espejo de esa creación. Pero un espejo que no refleja simplemente las cosas de fuera, sino que las forma y plasma de acuerdo con la forma en que las ve. Para Ficino, como para sus padres en la filosofía renacentista italiana, el hombre no es un esclavo de la naturaleza creadora; todo lo contrario, es un émulo, el que remata su obra perfeccionándola, corrigiéndola y depurándola. Allí donde el Creador, Dios, queda atrapado por su perfección, el hombre interviene y encuentra nuevas perfecciones. AI afianzarse el hombre, afianza a la creación, le da nuevas posibilidades, la recrea y recrea hasta el infinito. Tal es la doctrina de la filosofía dentro de la cual se ha formado Miguel Ángel. La Academia platónica de Florencia no sostiene otra cosa. Su ideal, la misión del hombre que Pico de la Mirándola le ha señalado en el mito, es borrar del mundo todo lo que tenga apariencia deforme, reconocer que todo lo amorfo participa en cierto modo de la forma. Para Ficino ésta es la suma de todo conocimiento filosófico religioso. Pero no basta reconocer, ver a través de la realidad concreta formas que están ocultas en ella; es menester, además, actuar, golpear, esculpir, sacar a flote. El artista es el ideal humano, el recreador de la creación. El hombre puede persuadirse de que el mundo sensible tiene una forma y una estructura sólo si continúa dándole forma. Para esta filosofía la belleza del mundo sensible no procede, en última instancia, del mundo sensible mismo, sino que es en cierto modo un medio en el cual la libre fuerza creadora del hombre se ejercita, medio que, además, hace que esa fuerza se reconozca a sí misma como tal. Leonardo, par de Miguel Ángel, escribía, "|Oh investigador de las cosas, no te gloríes de conocer las cosas que la naturaleza produce en su curso habitual! Alégrate, en cambio, de conocer la meta y término de aquellas cosas que tu espíritu ha trazado." 11 Ciencia y arte no son sino ins-

10 Symonds, op. cit., pág. 81.

11 Cassirer, op. cit., pág. 93 . 
trumentos de recreación de la naturaleza; la ciencia, nueva creación de la naturaleza, producida por la razón; el arte, segunda creación de la naturaleza producida por la imaginación. ¿Y qué es la moral sino la forma en que el hombre se recrea a sí mismo y hace de su ser un ente próximo a Dios o a la bestia? Dios crea, dice el Cusano, la realidad de las cosas; el hombre, en cambio, construye el orden de lo ideal, de lo que debe ser.

Hombres todavía con un pie en la Edad Media, no olvidaban viejas supersticiones y aún encontraban unidos sus destinos a sortilegios, magia, astrologia. ¿Pero no era esto contrario a una filosofía que hacfa del hombre mismo el escultor responsable de su existencia? ¿Cómo podían las estrellas y los astros determinar el destino de hombres que deberían ser sus propios escultores? Pico de la Mirándola no podía dejar de considerar este punto. La autodeterminación, la capacidad del hombre para hacerse a sí mismo y recrear la creación, estaba en contradicción con la creencia en la influencia de fuerzas extrañas a la voluntad humana. La voluntad, cierto, estaba limitada por las posibilidades del material de su creación, pero no limitada en la forma en que podía elegir dentro de esas limitaciones. Era esa voluntad la que decidía qué forma dar a la realidad que se le ofrecía dentro de las posibilidades de la misma. Por ello, en la obra del hombre no se debe admirar el material usado, sino la forma en que éste ha sido usado, no el material de la creación, sino la creación misma. No es la mejor estrella lo que ha hecho la grandeza de Aristóteles y Alejandro, sino la capacidad de los mismos para aprovechar y orientar las oportunidades que les ofrecia eso que llaman estrella. Lo que llamamos destino no viene de lo alto, no es obra de ningún astro o estrella, sino surge de lo más hondo del hombre, de esa voluntad de que le ha hecho don especial el Creador. "Ante todo ordenamos ese ciclo que se encuentra intelectualmente en nosotros mismos - dice Giordano Brunoy luego aquel otro visible que se presenta en forma corporal ante nuestra vista." 12 Arranquemos de nosotros mismos los obstáculos que nos impiden actuar antes de enfrentarnos a los que nos obstaculicen en el exterior. "Quitemos del cielo de nuestro espíritu - agrega Bruno- la Osa de la deformidad, la Flecha de la envidia, el Caballo de la liviandad, el Can de la maledicencia, la Perra de la adulación, desterremos a Hércules de la Violencia, a la Lira de la conspiración. . . , al Cafeo de la dureza de corazón. Cuando hayamos purificado así nuestra morada y de este modo hayamos creado nuevamente nuestro cielo, campearán nuevas constelaciones, influjos y fuerzas, nuevos destinos, pues todo depende de este mundo superior... Purifiquemos nuestro impulso interior: así no será difícil qué, partiendo de la nueva forma del mundo interior, logremos reformar el sensible y exterior." 13 Otra vez el mundo interior, lo que hace del hombre un hombre determina la recreación del 
mundo exterior. El hombre no surge dentro del mundo para simplemente vivirlo, sino para transformarlo, hacerlo a la imagen y semejanza del que lleva dentro o del que desde dentro puede ver en el exterior. Mundo interno que le permite taladrar el externo y encontrar en él formas extraordinarias de belleza, bondad, verdad y toda la gama de valores que el hombre puede descubrir o proyectar, según se quiera. Pomponazzi, como Ficino, buscando concilar a Aristóteles con Platón, insisten, una y otra vez, en que la imagen del mundo exterior parece formarse de la del mundo interior.

Tal es la filosofía, estética del universo, que circunda a Miguel Ángel y hace de su arte uno de los más extraordinarios ejemplos vivos de la misma. Un arte que tiene como centro al hombre, al hombre de carne y hueso, transformado en divino. Ese hombre cuyos músculos, nervios y carne parecen latir en el duro mármol; ese hombre que es, al mismo tiempo, la expresión de la naturaleza humanizada y la del hombre elevado a divinidad. Arte en que se confunde lo divino con lo humano, y que es al mismo tiempo proyección del mundo interno de un hombre, Miguel Angel. Lo que mejor traza cada artista - según Miguel Ángel- es su propio retrato; y en este sentido proyectó, con su arte, la imagen que del hombre tenía a través de sí mismo. Nada que no tuviese asiento en su interior podía ser expresado en el exterior. Por ello protesta frente a las exigencias a que se le quiere someter para el término de una obra que aún no sabe como expresar. "Monseñor - dice-: Vuestra señoría me manda decir que debo ponerme a pintar y dejar toda ansiedad. Contesto que se pinta con la cabeza y no con las manos; y aquél que no puede dominar su cabeza produce una obra que le avergüenza." 14 Nada que no sea producto de la libertad creadora, de esa libertad donada por el Creador para hacer posible la recreación permanente de su ya perfecta obra. Más allá de la naturaleza que, como el hombre de Pico de la Mirándola, poseía, pero para trascenderla y hacerla materia de su recreación. El propio Miguel Ángel es eso y por ello sobre él caben las palabras de Ariosto: "La naturaleza le hizo y después rompió el molde." ${ }^{15}$

LEOPOLDO ZEA 